\title{
Total and free iodothyronines profile in the donkey (Equus asinus) over a 12-month period
}

\author{
Esterina Fazio, Pietro Medica, Cristina Cravana, Adriana Ferlazzo \\ University of Messina, Faculty of Veterinary Medicine, Department of Morphology, Biochemistry, Physiology \\ and Animal Production, Unit of Veterinary Physiology, Italy
}

Received July 26, 2010

Accepted May 16, 2012

\begin{abstract}
Several studies show the correlation between thyroid function and reproductive activity in horses, but no data are available in donkeys. The aim of this study was to determine physiological thyroid changes occurring in 10 pregnant and 14 barren donkeys over a period of 12 months. Blood samples were collected monthly from the jugular vein of pregnant and barren donkeys from June 2008 to June 2009. No significant differences $(P<0.05)$ in iodothyronine concentrations were observed between pregnant and barren donkeys in the same month. Seasonal total thyroxine $\left(\mathrm{T}_{4}\right)$ and free triiodothyronine ( $\left.\mathrm{fT}_{3}\right)$ patterns remained unmodified, regardless of physiological state, with the lowest $\mathrm{T}_{4}$ levels at September and the highest at February, and the lowest $\mathrm{fT}_{3}$ levels at June and the highest at July, in both pregnant and barren donkeys. Ranges of total triiodothyronine $\left(\mathrm{T}_{3}\right)$ concentrations in pregnant donkeys over a 12 months period ranged from 1.57 to $2.90 \mathrm{nmol} / \mathrm{l}$, $\mathrm{T}_{4}$ from 31.01 to $63.67 \mathrm{nmol} / \mathrm{l}, \mathrm{fT}_{3}$ from 3.15 to $15.52 \mathrm{pmol} / 1$ and free thyroxine (fT $\mathrm{f}_{4}$ ) from 22.47 to $33.69 \mathrm{pmol} / 1$. Mean $\mathrm{T}_{3}$ concentrations in barren donkeys over a 12 months period ranged from 1.64 to $3.37 \mathrm{nmol} / 1, \mathrm{~T}_{4}$ from $42.95 \mathrm{nmol} / 1$ and $61.90 \mathrm{nmol} / 1, \mathrm{fT}_{3}$ from 3.15 to $11.19 \mathrm{pmol} / 1$ and $\mathrm{fT}_{4}$ from 25.46 to $35.06 \mathrm{pmol} / 1$. This is the first study that provided a seasonal thyroid hormonal profile in healthy barren and pregnant donkeys.
\end{abstract}

Thyroid gland, reproduction, seasonality

The thyroid system is involved during physical and psychological challenges in domestic animals through the release of iodothyronines (Anderson et al. 1988; Hegstad-Davies 2006; Fazio et al. 2007). A relationship between thyroid function and seasonal reproductive activity was investigated in mares (Huszenicza et al. 2000) and significant differences in plasma thyroxine concentrations were observed between cyclic and anoestrous mares during anovulatory season (Fitzgerald and Davison 1998).

Many reproductive aspects in donkey show close similarity with the mare (Ginther et al. 1987; Lemma et al. 2006; Carluccio et al. 2008). Only few studies have been carried out on the physiology of reproduction in donkeys (Henry et al. 1998; Pugh 2002; Carluccio et al. 2007; Taberner et al. 2008) but no data are available on the thyroid function in this species.

The current study aimed to investigate the seasonal profile of thyroid hormones in pregnant and barren donkeys over the period of 12 months.

\section{Materials and Methods}

\section{Experimental animals}

The study was carried out on a total of 24 clinically healthy Ragusana donkeys, aged 4-13 years, living on a farm located in Southern Sicily at Agrigento (37 19' 19" N latitude; $13^{\circ} 35^{\prime} 23^{\prime \prime}$ E longitude). The breeding season of donkeys in Sicily occurs from February to July. The study took place from June 2008 to June 2009. The animals were divided into two groups according to the physiological state (Group 1 with 10 pregnant donkeys; Group 2 with 14 barren donkeys). The animals were kept in paddocks during the day and in $20.9 \mathrm{~m}^{2}$ individual boxes at night, with inter-individual visual contact. They were familiar with their group members.

Both barren and pregnant donkeys had free access to pasture during the day and they were also individually fed with $2 \mathrm{~kg}$ of a grain supplement, straw and vetch hay twice a day. The composition and quantity of individual

Address for correspondence:

Esterina Fazio

Department of Morphology, Biochemistry, Physiology and Animal Productions Unit of Veterinary Physiology Faculty of Veterinary Medicine

98168 Messina, Italy
Phone: +39903503583

Fax: +39903503975

E-mail: esterina.fazio@tin.it

http://actavet.vfu.cz/ 
supplement was equal between groups 1 and 2 in order to minimize the effect of different diets on the variables studied.

Donkeys of group 1 became pregnant at the same time of the year (April-June) and the pregnancy was nearly of the same duration in all animals studied. The stage of pregnancy at the time of blood sampling was different in all animals studied, and the data were normalized in relation to medical history and confirmed by the timing of parturition that occurred 5 to 10 days after the final blood sampling. Consequently, at the beginning of the first month of sampling (June), pregnant donkeys were not at the same month of pregnancy. They showed normal pregnancy and foaled spontaneously, eutocic delivery, after $372.3 \pm 5.48$ days of pregnancy. All foals were healthy and viable. Donkeys of Group 2 were selected as control.

\section{Blood sampling}

Blood samples were taken from the jugular vein once monthly over the 12 months. All samples were taken between 7.00 and 9.00 in the morning to minimize the effect of the circadian rhythm on hormone measurements, in quiet conditions by the same operator. Blood samples were collected in evacuated tubes (Venoject, Terumo ${ }^{\circledR}$; Belgium) without anticoagulant and were, immediately after withdrawal, refrigerated at $4{ }^{\circ} \mathrm{C}$ and were subsequently (within $1 \mathrm{~h}$ ) centrifuged for $15 \mathrm{~min}$ at $1500 \times \mathrm{g}$. Serum was stored in polystyrene tubes at $-20^{\circ} \mathrm{C}$ and assayed for triiodothyronine $\left(\mathrm{T}_{3}\right)$ thyroxine $\left(\mathrm{T}_{4}\right)$, free triiodothyronine $\left(\mathrm{fT}_{3}\right)$ and free thyroxine $\left(\mathrm{fT}_{4}\right)$.

\section{Variables and methods}

Serum total $\left(\mathrm{T}_{3}, \mathrm{~T}_{4}\right)$ and free $\left(\mathrm{fT}_{3}, \mathrm{fT}_{4}\right)$ iodothyronine concentrations were analysed in duplicate using a commercial EIA Kits (RADIM, Pomezia, Roma, Italy). Sensitivities of the assays were as follows: $0.24 \mathrm{nmol} / 1$ for $\mathrm{T}_{3}, 29.63 \mathrm{nmol} / 1$ for $\mathrm{T}_{4}, 0.15 \mathrm{pmol} / 1$ for $\mathrm{fT}_{3}$ and $<12.87 \mathrm{pmol} / 1$ for $\mathrm{fT}_{4}$. Precision was evaluated determining the repeatability and reproducibility of the assay (intra- and interassay variability, CVs), on 3 different sera at different total and free iodothyronine concentrations. The respective intra- and interassay CVs were as follows: $7.3 \%$ and $11.4 \%$ for $\mathrm{T}_{3}, 2.3 \%$ and $5.7 \%$ for $\mathrm{T}_{4}, 4.2 \%$ and $11.9 \%$ for $\mathrm{fT}_{3}, 6.6 \%$ and $9.6 \%$ for $\mathrm{fT}_{4}$, respectively.

\section{Statistical analysis}

Data are presented as means \pm standard deviation (SD). Statistical analysis was done by one way repeated measures analysis of variance (RM-ANOVA). Significant differences of all the months versus each other and between pregnant and barren donkeys were established using Bonferroni's multiple comparison test. The level of significance was set at $P<0.05, P<0.02$ and $P<0.001$. All calculations were performed using the PRISM package (GraphPad Software Inc., San Diego, CA). The relation between thyroid hormone concentrations was evaluated by correlation and linear regression.

\section{Results}

Mean total and free iodothyronine concentrations of pregnant and barren donkeys over a period of 12 months \pm standard deviation are reported in Figs 1 and 2, respectively. Compared to the previous month, significantly higher concentrations of $\mathrm{fT}_{3}$ were observed in pregnant donkeys in September $(P<0.01)$ and $\mathrm{fT}_{4}$ in December $(P<0.02)$. Pregnant donkeys showed the lowest concentrations of $\mathrm{T}_{3}$ in March, $\mathrm{T}_{4}$ in September, $\mathrm{fT}_{3}$ in June and $\mathrm{fT}_{4}$ in February, and the highest concentrations of $\mathrm{T}_{3}$ in the successive June, $\mathrm{T}_{4}$ in February, $\mathrm{fT}_{3}$ in July and $\mathrm{fT}_{4}$ in December.

Compared to the previous month, significantly lower concentrations of $\mathrm{T}_{3}$ in July $(P<0.02)$ and higher in the successive June $(P<0.001)$, lower concentrations of $\mathrm{T}_{4}$ in September $(P<0.05)$ and higher in August $(P<0.05)$ and in February $(P<0.05)$, lower $\mathrm{fT}_{3}$ concentrations in September $(P<0.01)$ were observed in barren donkeys.

Barren donkeys showed the lowest concentrations of $\mathrm{T}_{3}$ in May, $\mathrm{T}_{4}$ in September, $\mathrm{fT}_{3}$ in May and $\mathrm{fT}_{4}$ in March, and the highest concentrations of $\mathrm{T}_{3}$ in June, $\mathrm{T}_{4}$ in February, $\mathrm{fT}_{3}$ and $\mathrm{fT}_{4}$ in July.

No significant differences of total and free iodothyronine concentrations between pregnant and barren donkeys were observed. Triiodothyronine $\left(T_{3}\right)$ concentrations in pregnant donkeys over a 12-month period ranged from 1.57 to $2.90 \mathrm{nmol} / 1, \mathrm{~T}_{4}$ ranged from 31.01 to $63.67 \mathrm{nmol} / 1, \mathrm{fT}_{3}$ ranged from 3.15 and $15.52 \mathrm{pmol} / 1$ and free thyroxine $\left(\mathrm{fT}_{4}\right.$ ) from 22.47 and $33.69 \mathrm{pmol} / \mathrm{l}$.

However, a significant effect of season on $\mathrm{T}_{3}(P<0.001)$ and $\mathrm{fT}_{3}(P<0.001)$ changes in both pregnant and barren donkeys was observed. Significantly positive correlations between $\mathrm{T}_{3}: \mathrm{T}_{4}(\mathrm{r}=0.9832 ; P<0.05), \mathrm{T}_{3}: \mathrm{fT}_{3}(\mathrm{r}=0.9911 ; P<0.01)$ and $\mathrm{T}_{4}: \mathrm{fT}_{4}(\mathrm{r}=0.9949 ; P<0.01)$ were observed in pregnant donkeys, and significantly positive correlations between $\mathrm{fT}_{3}: \mathrm{fT}_{4}$ 


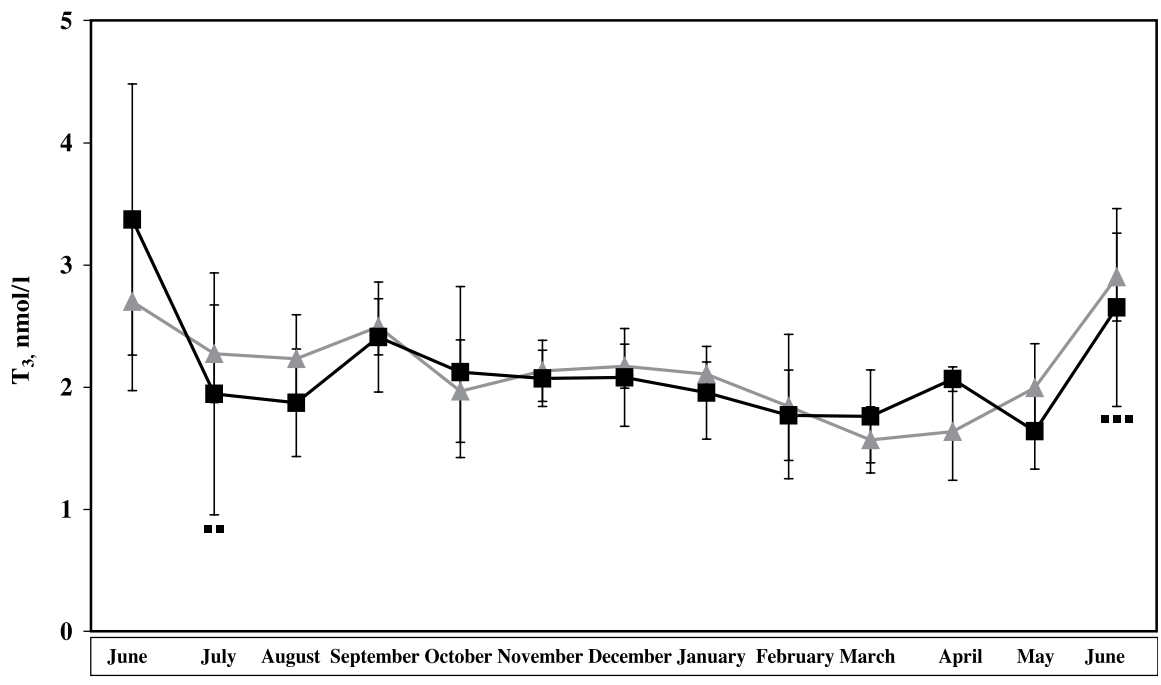

Pregnant $\rightarrow$ - Barren

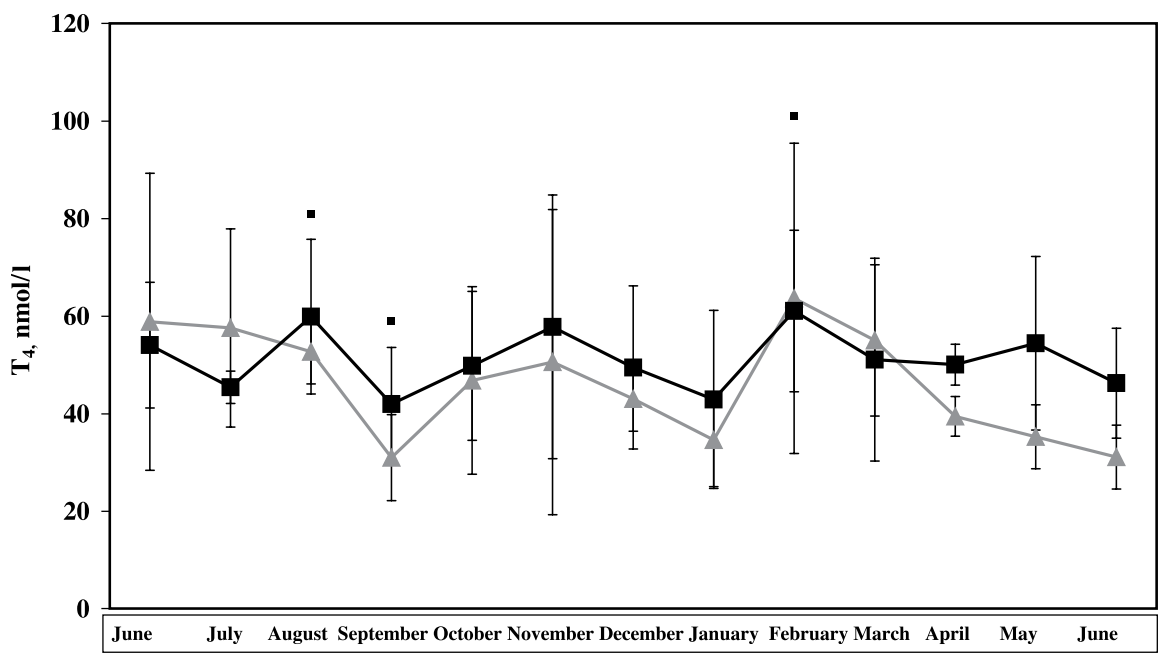

- Pregnant -B-Barren

Fig. 1. Seasonal serum total iodothyronine concentrations $\left(\mathrm{T}_{3}, \mathrm{~T}_{4}\right)$ of pregnant and barren donkeys $(\mathrm{Mean} \pm \mathrm{SD})$ over a 12 months period from June to the next June

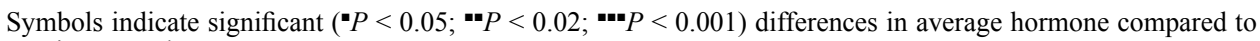
previous month

$(\mathrm{r}=0.9977 ; P<0.01), \mathrm{T}_{3}: \mathrm{fT}_{3}(\mathrm{r}=0.9966 ; P<0.01)$ and $\mathrm{T}_{4}: \mathrm{fT}_{4}(\mathrm{r}=0.9768 ; P<0.05)$ were observed in barren donkeys.

\section{Discussion}

Comparison of results obtained in donkeys with published data reported for horses reveals no discrepancies for circulating total and free iodothyronine concentrations 


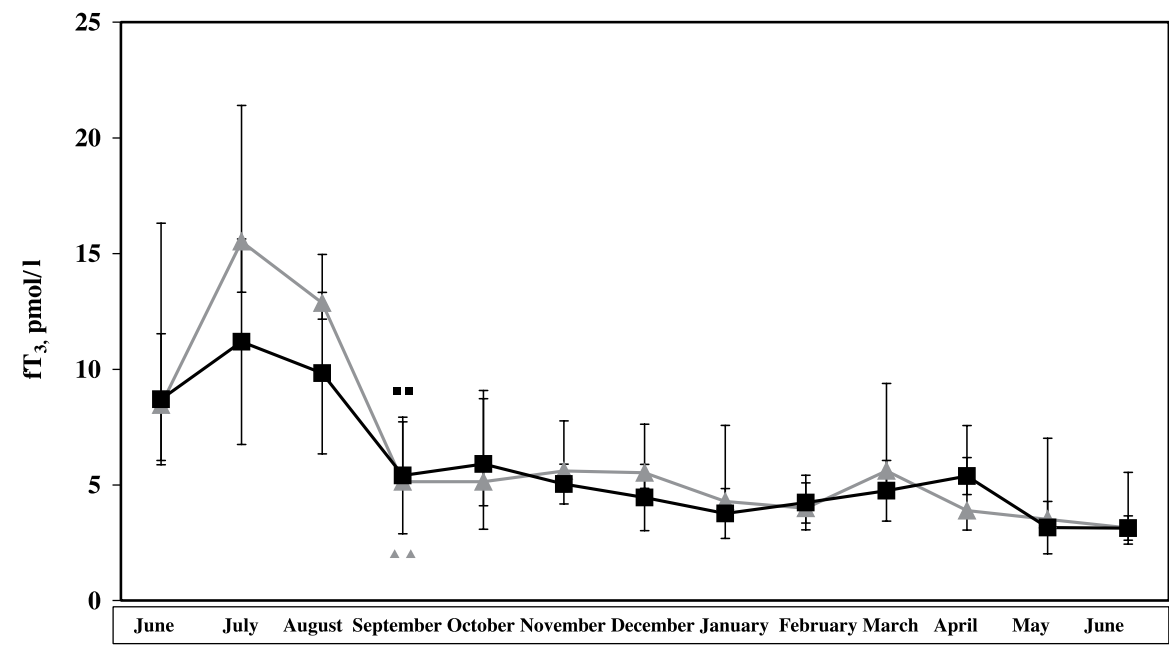

- Pregnant - -Barren

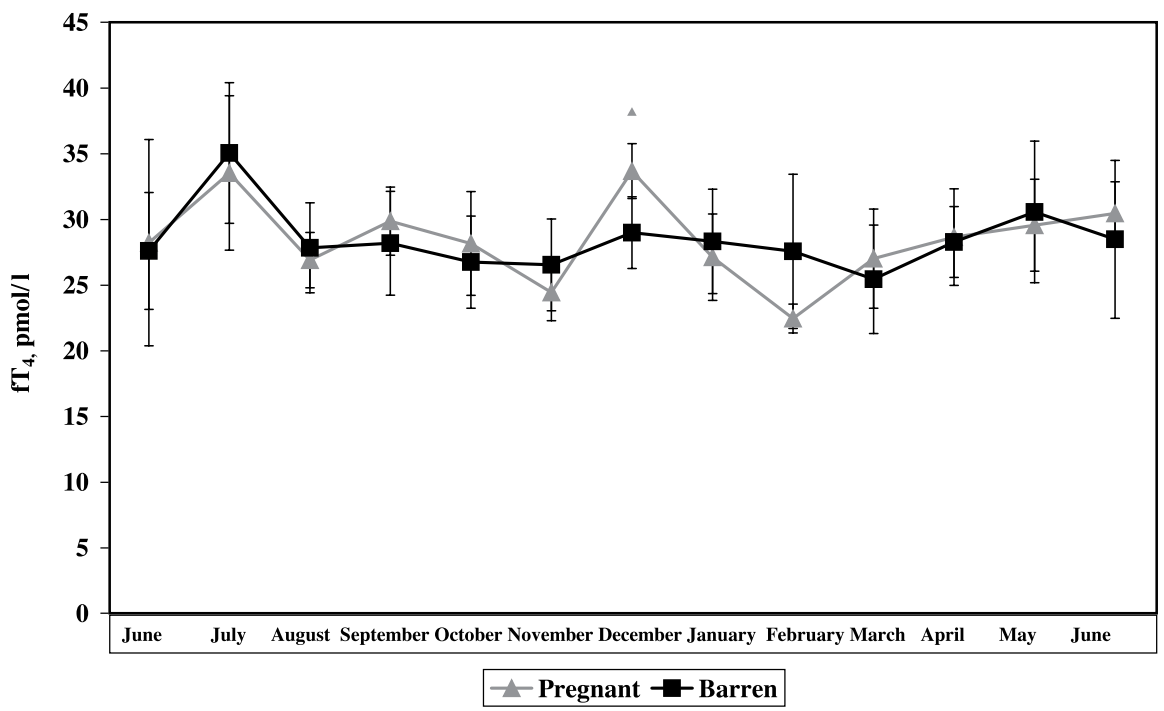

Fig. 2. Seasonal serum free iodothyronine concentrations $\left(\mathrm{fT}_{3}, \mathrm{fT}_{4}\right)$ of pregnant and barren donkeys $(\mathrm{Mean} \pm \mathrm{SD})$ over a 12 months period from June to the next June

Symbols indicate significant $\left({ }^{\Delta} P<0.05 ;{ }^{\Delta} P<0.01\right)$ differences in average hormone compared to previous month

(Anderson et al. 1988; Kaneko 1989; Flisińska-Bojanowska et al. 1991), but some variation might be due to differences in the techniques used. Some differences could be explained by the influence of results with physiological or geographic factors and different management.

The results did not exclude the fact that some stress conditions such as stabling or 
management (Hoffman et al. 1995; Malinowski et al. 1996; Christensen et al. 1997; Moons et al. 2005) and diet (Messer et al. 1995; Sticker et al. 1995; Powell et al. 2000) may determine higher $\mathrm{T}_{4}, \mathrm{fT}_{3}$ and $\mathrm{fT}_{4}$ concentrations in both barren and pregnant donkeys than data reported in horses. Stress conditions may be induced by blood drawing which was always performed in donkeys that were out to pasture. Moreover, the data obtained exclude possible influence of thyroid rhythms because blood sampling was always performed at the same time.

Data obtained in donkeys confirm previous data reported in horses, that showed a similar pattern of thyroid hormones, with higher $\mathrm{T}_{3}$ and $\mathrm{T}_{4}$ concentrations in barren than in pregnant mares (Flisińska-Bojanowska et al. 1991). In addition, the absence of significant differences of $\mathrm{T}_{3}$ and $\mathrm{T}_{4}$ concentrations between barren and pregnant donkeys in the same month of sampling confirms previous data observed in barren and pregnant broodmares (Meredith and Dobrinski 2004).

Although lower $T_{3}$ and $T_{4}$ concentrations in pregnant compared to barren donkeys are not significant, this trend could be indicative of their high utilization in general metabolism during pregnancy, as indicated by the positive significant correlation between $\mathrm{T}_{3}$ and $\mathrm{T}_{4}$ described only in pregnant donkeys. It is possible that these results could be due to high thyroidal activity of the foetus with a probable negative feedback on the maternal total iodothyronine concentrations. However, this hypothesis will require more information related to placental permeability to thyroid hormones in donkeys.

In addition, observation of unmodified seasonal $\mathrm{T}_{4}$ and $\mathrm{fT}_{3}$ patterns in both pregnant and barren donkeys with the lowest $\mathrm{T}_{4}$ concentrations in September and the highest in February, and the lowest $\mathrm{fT}_{3}$ concentrations in June and the highest in July, showed the probable existence of intrinsic seasonal changes of these hormones, irrespective of the physiological condition, indicating that thyroid hormone concentrations and pregnancy are not related in donkeys. The acrophase of $\mathrm{T}_{4}$ observed in barren donkeys in February confirms previous data reported for $\mathrm{T}_{4}$ in mares (Flisińska-Bojanowska et al. 1991). On the other hand, the acrophase of $\mathrm{T}_{3}$ observed in both barren and pregnant donkeys in June does not confirm previous data reported for $\mathrm{T}_{3}$ in mares, with acrophase occurring in July (Flisińska-Bojanowska et al. 1991).

The different seasonal pattern of total and free iodothyronines between pregnant and barren donkeys can be interpreted in terms of peripheral metabolism of thyroid hormones, although positive and significant correlations were observed between $\mathrm{T}_{3}: \mathrm{fT}_{3}$ and $\mathrm{T}_{4}: \mathrm{fT}_{4}$ in both pregnant and barren donkeys. Hence, maternal and foetal thyroid synthesis could be recognised as hormones that may enhance substantially the conversion of $\mathrm{T}_{4}$ to $\mathrm{T}_{3}$ in peripheral tissues, as demonstrated by the positive significant correlation between $\mathrm{T}_{3}$ and $\mathrm{T}_{4}$ observed only in pregnant donkeys. These changes may result subsequently in a temporary decrease in thyroid activity of pregnant females with no significant lower $\mathrm{T}_{3}, \mathrm{~T}_{4}$ and $\mathrm{fT}_{4}$ concentrations compared to barren females, and confirm that the utilization rates of thyroid hormones in mammals change unpredictably during pregnancy (Tomasi 1991).

On the other hand, the significant positive correlation observed between $\mathrm{fT}_{3}$ and $\mathrm{fT}_{4}$ only in barren donkeys could be due to preferential conversion of $\mathrm{fT}_{4}$ to $\mathrm{fT}_{3}$ that represents the active form of free iodothyronines.

In conclusion, although no significant differences between pregnant and barren donkeys were observed, the results showed a significant effect of season on $\mathrm{T}_{3}$ and $\mathrm{fT}_{3}$ concentrations in both pregnant and barren donkeys. These results confirm the active metabolic role of these iodothyronines in donkeys, as reported in previous studies in horses (Fazio et al. 2007). Data reported in this study are the first seasonal thyroid hormonal profile of barren and pregnant donkeys over a 12 months period. 


\section{References}

Anderson RR, Nixon DA, Akasha MA 1988: Total and free thyroxine and triiodothyronine in blood serum of mammals. Comp Biochem Physiol A 89: 401-404

Carluccio A, Panzani S, Tosi U, Faustini M, De Amicis I, Veronesi MC 2007: Efficacy of hCG and GnRH for inducing ovulation in the jenny. Theriogenology 68: 914-919

Carluccio A, De Amicis I, Panzani S, Tosi U, Faustini M, Veronesi MC 2008: Electrolytes changes in mammary secretions before foaling in jennies. Reprod Dom Anim 43: 162-165

Christensen RS, Malinowski K, Massenzio AM, Hafs HD, Scanes CG 1997: Acute effects of short-term feed deprivation and refeeding on circulating concentrations of metabolites, insuline-like growth factor I, insulinelike growth factor binding proteins, somatotropin, and thyroid hormones in adult geldings. J Anim Sci 75 : 1351-1358

Fazio E, Medica P, Cravana C, Messineo C, Ferlazzo A 2007: Total and free iodothyronine levels of growing thoroughbred foals: effects of weaning and gender. Livestock Sci 110: 207-213

Fitzgerald BP, Davison LA 1998: Thyroxine concentrations are elevated in mares which continue to exhibit estrous cycle during the nonbreeding season. J Equine Vet Sci 18: 48-51

Flisińska-Bojanowska A, Komosa M, Gill J 1991: Influence of pregnancy on diurnal and seasonal changes in cortisol, $\mathrm{T}_{3}$ and $\mathrm{T}_{4}$ levels in the mare blood serum. Comp Biochem Physiol A 98: 23-30

Ginther OJ, Scraba ST, Bergfelt DR 1987: Reproductive seasonality of the jenney. Theriogenology 27: 587-592

Hegstad-Davies RL 2006: A review of sample handling considerations for reproductive and thyroid hormone measurement in serum or plasma. Theriogenology 66: 592-598

Henry M, Lodi LD, Gastal MMFO 1998: Sexual behaviour of domesticated donkeys (Equus asinus) breeding under controlled or free range management systems. Appl Anim Behav Sci 60: 263-276

Hoffman RM, Kronfeld DS, Holland JL, Greiwe-Crandell KL 1995: Preweaning diet and stall weaning method influences on stress responses in foals. J Anim Sci 73: 2922-2930

Huszenicza C, Nagy P, Juhàsz J, Kòròdi P, Kulcsàr M, Reiczigel J, Guillaume D, Rudas P, Solti L 2000: Relationship between thyroid function and seasonal reproductive activity in mares. J Reprod Fertil Suppl 56: 163-172

Kaneko JJ 1989. Normal blood analyte values in large animals. In: Clinical Biochemistry of Domestic Animals, Kaneko JJ, (Ed.), Academic Press, Inc, San Diego, NY, Appendix VII, pp. 886-891

Lemma A, Schwartz HJ, Bekana M 2006: Application of ultrasonography in the study of the reproductive system of tropical jennies (Equus asinus). Trop Anim Health Prod 38: 267-274

Malinowski K, Christensen RA, Hafs HD, Scanes CG 1996: Age and breed differences in thyroid hormones, insulin-like growth factor (IGF)-I and IGF binding proteins in female horses. J Anim Sci 74: 1936-1942

Meredith TB, Dobrinski I 2004: Thyroid function and pregnancy status in broodmares. J Am Vet Med Assoc 224: $892-894$

Messer NT, Johnson PJ, Refsal KR, Nachreiner RF, Ganjam VK, Krause GF 1995: Effect of food deprivation on baseline iodothyronine and cortisol concentrations in healthy, adult horses. Am J Vet Res 56: 116-121

Moons CPH, Laughlin K, Zanella AJ 2005: Effects of short-term maternal separations on weaning stress in foals. Appl Anim Behav Sci 91: 321-335

Powell DM, Lawrence LM, Fitzgerald BP, Danielsen K, Parker A, Siciliano P, Crum A 2000: Effect of short-term feed restriction and calorie source on hormonal and metabolic responses in geldings a small meal. J Anim Sci 78: $3107-3113$

Pugh DG 2002: Donkey reproduction. Proc Am Assoc Equine Pract 48: 113-114

Sticker LS, Thompson DL Jr, Fernandez JM, Bunting LD, DePew CL 1995: Dietary protein and (or) energy restriction in mares: plasma growth hormone, IGF-I, prolactin, cortisol, and thyroid hormone responses to feeding, glucose, and epinephrine. J Anim Sci 73: 1424-1432

Taberner E, Medrano A, Peña A, Rigau T, Miró J 2008: Oestrus cycle characteristics and prediction of ovulation in Catalonian jennies. Theriogenology 70: 1489-1497

Todini L, Malfatti A, Salimei E, Fantuz F 2010: Measurement of thyroid hormones in donkey (Equus asinus) blood and milk: validation of ELISA kits and evaluation of sample collection, handling and storage. J Dairy Res 77: 419-424

Tomasi TE 1991: Utilization rates of thyroid hormones in mammals. Comp Biochem Physiol A 100: 503-516 